\title{
Arbor
}

\section{El fin de la aventura}

\author{
Joaquín $M^{a}$ Córdoba
}

Arbor CLXXX, 711-712 (Marzo-Abril 2005), 861-868 pp.

Si echamos la vista atrás y observamos con atención la historia europea y oriental de comienzos del siglo XX, comprenderemos que hemos llegado al final de la aventura. Porque al paso de los últimos enamorados del «voyage en Orient», informadores y exploradores muy especiales transitaron entonces por pistas y ciudades. Y en su asalto final a los restos del Imperio Otomano, las potencias vencedoras de la I Guerra Mundial se repartirían colonias y áreas de influencia. Pero antes habían ido trazando sus planes a largo plazo, porque también en Oriente Próximo y bajo cuerda, Inglaterra, Francia y Alemania jugaron su particular «gran partida» antes de la Gran Guerra. En 1899, un año despues de que Alemania hiciera su entrada en escena, Inglaterra firmó un pacto secreto con Mubarak al-Sabah, cuya tribu vivía en los alrededores de un poblado situado en la costa de la provincia de Basra, llamado Kuwait ${ }^{1}$. Con el cinismo calculador que siempre caracterizó la construcción y defensa de su imperio, los ingleses sumaron este enclave al rosario de puestos con los que ya dominaban la navegación del Golfo Pérsico, tomando de nuévo así la iniciativa y conquistando una posición vital en el tablero en el que se iban a jugar dos partidas decisivas; el ferrocarril y el petróleo.

$\mathrm{Y}$ es que en el curso del último tercio del siglo XIX, aunque jurídicamente al menos Egipto y el Canal de Suez siguieran formando parte del Imperio Otomano, de hecho eran ambos predios británicos ${ }^{2}$, pese a la profunda irritación turca. Al asegurarse Inglaterra esa nueva ruta a la India, la tradicional por Mesopotamia dejó de ser primordial, aunque en las costas del Golfo se mantuvieran enclaves de paso valiosos, como los emiratos de la Costa de la Tregua, Bahrain y el puesto de Bushir. Sin embargo, el viaje a Oriente del káiser Guillermo II rompía un statu quo que Gran Bretaña deseaba mantener como fuera. En 1898, la visita del emperador alemán tenía dos intenciones, una puramente económica y polí- 
tica -fortalecer la alianza entre ambos imperios, asegurarse la concesión del ferrocarril desde Ánkara y Konya hasta Basra (el famoso BagdadBahn), y el suministro de armamento moderno para el ejército turco-, y otra religiosa y cultural, pues Guillermo II quería ceder una finca en Jerusalén para la edificación de la iglesia de la Dormitio Sanctae Mariae Virginis, y visitar las ciudades antiguas de Palestina y Siria. Estuvo en Jerusalén y Damasco, visitó las imponentes ruinas de Baalbek y sin duda llevado de su sincero interés por la arqueología y la ciencia ${ }^{3}$, resolvió impulsar la investigación alemana en Oriente. Poco después, Otto Puchstein trabajaría en Baalbek y Robert Koldewey en Babilonia ${ }^{4}$. Con ellos empezaba la moderna arqueología en Oriente Próximo.

El caso es que la construcción del ferrocarril y las suspicacias de unos y otros vinieron a decidir algunos de los viajes más minuciosos de comienzos de siglo, que se verían acompañados por los de estudiosos animados de una pasión más confesable: el descubrimiento de la Antigüedad. Por las rutas de Oriente se movieron entonces Max von Oppenheim, Pierre Loti, Gertrud Bell, Ernst Herzfeld, Thomas Lawrence y muchos más, y con ellos tal vez se cruzaron los españoles Antonio Muñoz Degrain, Vicente Blasco Ibañez y el padre Buenaventura Ubach, honrosos epígonos de nuestros viajeros a Oriente.

Es muy posible que la figura más interesante de la primera mitad del siglo XX sea la del barón Max von Oppenheim, diplomático, viajero y arqueólogo ${ }^{5}$. Hijo de una familia notable en las finanzas, doctor en derecho, tras un primer viaje a Oriente comenzó sus estudios de árabe en Wiesbaden y Berlín, donde conoció al más célebre explorador alemán de África, Gerhard Rohlfs, que le animó a realizar empresas que dignificaran a su patria. En 1892 viajó a El Cairo, para perfeccionar su árabe, decidiendo entonces "meterse en el espíritu del Islam». E inflamado por su pasión y los alientos de G. Rohlfs, en 1893 emprendió un gran viaje desde Beirut al Golfo Pérsico, en el curso del cual cruzó las montañas del Haurán, el desierto de Palmyra y tras pasar el Éufrates en Deir Zor, subió hasta Mossul y descendió todo el curso del Tigris por la orilla izquierda. La publicación de su aventura ${ }^{6}$ iba a revelarle como el más importante viajero científico de su tiempo, una nueva especie propia del siglo XX. Pero sin profesión ejercida ni futuro definido hasta entonces, en 1896 la presión familiar le llevó al Ministerio de Asuntos Exteriores alemán, para el que prestaría sus servicios en la legación alemana de El Cairo durante trece años. Allí redactó hasta 500 informes muy variados sobre el mundo islámico, que el mismo káiser estimó sobremanera. Su perfecto entendimiento con los árabes, sus viajes y sus actividades des- 


\section{El fin dela aventura}

pertaron las suspicacias de los ingleses, que le suponían una especie de espía, pero lo cierto es que nunca pasó de ser un erudito que amaba el mundo árabe y que ejercía su condición de Secretario de Legación, intentando compaginarla con su verdadera pasión ${ }^{7}$. En 1899 llevó a cabo otro gran viaje por Palestina y al Yazira - una región prácticamente desconocida entonces, y en la que descubriría Tell Halaf-, cuyos resultados serían publicados dos años después ${ }^{8}$. Su vocación por la etnología y la arqueología se iba acentuando, al tiempo que cumplía con sus obligaciones diplomáticas. Pero en 1909 abandonó el servicio exterior para dedicarse a la que consideraba la labor de su vida: la excavación de Tell Halaf y el estudio los beduinos. Las excavaciones arqueológicas se llevarían a cabo en dos fases (1911-1913 y 1927), en 1913 realizaría un nuevo viaje por al Yazira y sus libros irían saliendo luego y convirtiéndose en obras de referencia, como la monumental Die Beduinen y las memorias definitivas de Tell Halaf 9 . Murió ya octogenario, a poco de finalizar la II Guerra Mundial. La inscripción de su lápida funeraria testimonia que con él moría quizás el último de los grandes viajeros de esta historia ${ }^{10}$.

La vida de Max von Oppenheim se cruzó con la de otros curiosos personajes de la época, como Gertrud Bell -a la que juzgó en El Cairo como "muy inteligente e interesante»-o Thomas E. Lawrence, al que conoció en una visita al yacimiento de Karkemis. Lawrence por cierto estimaba que "Von Mittelmeer zum Persischen Golf» era el mejor libro que había conocido sobre el área ${ }^{11}$. Aparentemente muchas cosas aproximaban la vida del alemán y de ambos ingleses, pero su evolución sería radicalmente distinta, no tanto por la guerra cuanto por sus convicciones personales. Max von Oppenheim siempre falto de arrogancia, respetuoso y sinceramente integrado con los pueblos, volcado finalmente en la arqueología: los británicos, diletantes primero en la arqueología, hablando siempre de "los orientales" -con el típico simplismo reduccionista del colonalismo-, de unas gentes a las que G. Bell consideraba "como niños", y que al fin se entregarían en alma y cuerpo a los servicios secretos del Imperio Británico.

Antes de que estallara la I Guerra Mundial, algunos otros viajeros caminaron por Oriente, como el célebre marino y escritor francés Pierre Loti, que entre el 17 de abril y el 6 de junio de 1900 cruzó Irán, desde la orilla del Golfo Pérsico en Bushir, hasta la del Caspio en Enzeli, pasando por sitios tan emblemáticos como la famosa Isfahán, y escribiendo luego un libro lleno de las virtudes y defectos típicos de su literatura ${ }^{12}$. En 1905, el mismo año en el que Gertrud Bell, hija de una de las grandes familias de la industria británica, que había aprendido árabe y persa al vi- 
vir en Teherán con su tío, embajador en Irán, emprendiera su tercera expedición por Beirut, Jerusalén y el Yebel Drus -del que enviaría por cierto, y como solía hacer en cada viaje, un informe al Foreing Office y al Indian Bureau-13, el pintor español Antonio Muñoz Degrain visitó Palestina y Siria, donde esbozó su mágica serie de cuadros de Tierra Santa, que suponen una visión asombrosa del paisaje oriental ${ }^{14}$. Poco después, Vicente Blasco Ibáñez emprendería un viaje a Oriente -sintetizado en su estancia turca y en la descripción de Constantinopla hecha en su famoso libro-, y por las mismas rutas que lo habían hecho ya tantos antepasados en la aventura, el sabio monje Buenaventura Ubach viajaría por el Sinaí -del que escribiría un interesante libro-, Líbano, Palestina y Transjordania, recogiendo notas, fotografías y objetos para las que serían sus grandes realizaciones en Montserrat.

Pocos años antes de la guerra, las realidades políticas y el mismo presente histórico estaban colocando en su sitio real las tradicionales imágenes literarias y artísticas del orientalismo. Los decorados y el brillante vestuario del Oriente soñado a través de las Mil y una noches, exhibidos en la Ópera de París en 1910, por los Ballets Rusos de Sergey Diaghilev en su versión de Scherezade de Rimsky Korsakov ${ }^{15}$, podían despertar una supuesta moda oriental en los vestidos de las damas parisinas, pero casaban mal con la realidad descarnada de las fotografías del arquitecto Maurice Pillet, tomadas en su viaje a Susa en $1912^{16}$, o tantos otros miles de instantáneas traídas por centenares de viajeros y visitantes. La pintura ya no podía permitirse evocaciones, y algunos años después, cuando en $1916 \mathrm{D}$. W. Griffith estrenara su película "Intolerance» ${ }^{17}$, el cine tomaría el testigo de la recreación de los mitos y la supuesta realidad oriental. Pero antes había que pasar la prueba de la guerra y la traumática creación de las naciones modernas de Oriente.

La I Guerra Mundial liquidó los restos del Imperio Otomano en Oriente y al imperio mismo. La guerra confirmó también las verdaderas tendencias de sujetos antes dudodos, como T. E. Lawrence ${ }^{18}, \mathrm{G}$, Bell o St John Philby ${ }^{19}$, verdaderos "agentes imperiales" como dice E. W. Said, que llamados por D. H. Hogarth al Bureau de El Cairo, se convertirían en los "expertos" que iban a definir las fronteras de los nuevos países, naturalmente siempre al mejor servicio de la Gran Bretaña ${ }^{20}$. Con la paz, la voluntad inglesa de olvidar promesas e imponer sus planes quedó pronto de manifiesto con el brutal aplastamiento de la rebelión iraquí, que en 1920 implicó el bombardeo de las tribus con gases y la carnicería represiva decidida por Percy Cox, protector de Gertrud Bell ${ }^{21}$. Por su parte, los franceses no fuerón menos explícitos en la liquidación de la breve monarquía 


\section{El fin dela aventura}

de Faysal en Damasco. El tratado de Sévres, que en agosto había desmantelado el imperio turco, abrió paso al reparto entre Francia e Inglaterra, y el viejo sueño hachemita de un sólo gran reino árabe -prometido por los ingleses para conseguir el apoyo de Hussein contra los turcos- se desvaneció. En 1921, W. Churchill y los responsables británicos en Oriente se reunieron en El Cairo y ofrecieron a Faysal la corona de Iraq, reservándose el dominio del país como mandato de la Sociedad de Naciones: por el oeste, sin embargo, tuvieron que aceptar como hecho consumado la monarquía de su hermano Abdallah en Jordania. Mas con Hussein, padre de ambos y todavía soberano en La Meca no hubo posible acuerdo, dolido por el engaño y las maniobras británicas. Pero en 1924, Ibn Saud del Nayad expulsó a los hachemitas y se proclamó rey con apoyo inglés ${ }^{22}$ : los intereses occidentales en los yacimientos petrolíferos de Hasa estaban asegurados.

El Oriente que salió de la I Guerra Mundial era un espacio dividido, conmovido por el despertar del nacionalismo árabe, que aspiraba a sacudirse el dominio de Francia e Inglaterra. Algunos curiosos volvieron a cruzar por sus rutas, pero la época gloriosa del redescubrimiento de los pueblos, los paisajes y las culturas había terminado. En 1922-1923, el padre Ubach viajó por Siria e Iraq, visitando Bagdad, Babilonia y Ur, y en abril de 1926, el capitan Rafael Martínez Esteve se estrellaba con su avión en el desierto de Iraq, comenzando una épica marcha en busca de la vida, de la que saldría un libro lleno de imágenes que cierran poéticamente la historia de nuestros viajeros y, en cierta forma, la de todos. Porque el resto sería otra cosa, aunque el viaje de Agatha Christie en 1930, invitada por la esposa de L. Woolley a visitar la famosa excavación de Ur, decidiera su matrimonio con M. E. L. Mallowan, su participación posterior en las excavaciones de su marido y novelas como «Murder in Mesopotamia» $(1936)^{23}$; y aunque la legendaria expedición Citroën al Asia Central, de los años 1931-1932, que cruzó Siria, Iraq e Irán antes de introducirse en Afganistán, la India y China, reportara un enorme acervo de documentación de todo tipo para la arqueología y la historia, la etnografía, la geología y la zoología en general de tan vasta región ${ }^{24}$. Herederos quizás de la vieja tradición serían la suiza Ella Maillart (1903-1997), con sus incesantes viajes por el antiguo Turkestán, Irán, Afganistán y otras regiones de Oriente ${ }^{25}$, y el británico Wilfred Thesiger (1910-2003), peregrino por los desiertos de Arabia y habitante durante largos años de las marismas de Iraq $^{26}$.

Aunque, probablemente, ni siquiera ellos. Cuando los viajeros españoles recordados cruzaron sus pasos con los últimos europeos, Oriente seguía sien- 
do «el otro más cercano». Pero la aventura se había acabado. Lo paradójico es que todavía hoy, Oriente sigue siendo nuestro otro yo más cercano.

\section{Notas}

1 Ni las autoridades turcas ni la población árabe de Basra aceptaron la jugada. Mubarak tuvo que reconocer ante el gobierno turco que seguía siendo parte de Basra e Iraq, pero la "relación especial» con los británicos se mantuvo. En 1914 éstos aprovecharon el comienzo de la guerra para ocupar un perímetro, y tras su finalización sancionaron la ocupación. Los diferentes gobiernos de Iraq -incluido el de la monarquía de Faysal- nunca reconocieron la legalidad de Kuwait. SAINT-Prot, Ch. (1999): Histoire de l'Irak. De Sumer à Saddam Husseim. Ellipse, Paris, pp. 83-84.

2 SELlier, J. y A. (1993): Atlas de los pueblos de Oriente. Oriente Medio, Cáucaso, Asia Central. Acento Editorial, Madrid, pp. 54-56.

3 En la época de su formación, el káiser había seguido disciplinas humanísticas y arqueología, y tras su abdicación publicó algunos estudios que lo evidencian como Vergleichende Zeittafel der Vor- und Frühgeschichte Vorderasien, Ägyptens und der Mittelmeerländer (1936) o Das Königtum im alten Mesopotamien (1938). Para su visita y sus intereses véase HÜBNER, U. (1999): «Der Besuch Wilhelms II. in Baalbek», en VAN EsS, M. y WEBER, Th. (eds.): Baalbek: im Bann römischer Monumentalarchitektur. Verlag Philipp von Zabern, Mainz am Rein, pp. 122-124.

4 Sobre el empeño personal del káiser en la apertura y mantenimiento de las excavaciones arqueológicas alemanas en Oriente, y sobre su respaldo a la Deutsches OrientGesellschaft, véase WILHELM, G.: «Einführung», en WILHELM, G. (ed.) (1988): Zwischen Tigris und Nil. 100 Jahre Ausgrabungen der Deutschen Orient-Gesellschaft in Vorderasien und Ägypten. Verlag Philipp von Zabern, Mainz am Rhein, pp. 5-13.

5 CHOLIDIS, N. y MARTín, L. (2002): Der Tell Halaf und sein Ausgräber Max Freiherr von Oppenheim. Vorderasiatisches Museum, Staatliche Museen zu Berlin, Berlin. TEICHMANN, G. y VöLGER, G. (eds.) (2003): Faszination Orient. Max von Oppenheim. Forscher, Sammler, Diplomat. DuMont Literatur und Kunst Verlag, Köln. Una breve aproximación en CóRDoBA, J. M ${ }^{\mathrm{a}}$ (2002-2003): «Max von Oppenheim (1860-1946) y el descubrimiento de Tell Halaf», Cuadernos del Seminario Walter Andrae, 5, pp. 43-57.

6 VoN OPPENHEIM, M. Freiherr (1899: 1900): Vom Mittelmeer zum Persischen Golf. 2 volúmenes, Berlin.

7 KRÖGER, M. (2003): "Mit Eifer ein Fremder. Im Auswärtigen Dienst», en TEICHMANN, G. y VöLGER, G. (eds.), op. cit. 106-139. M. Kröger deja meridianamente claro que Max von Oppenheim nunca sirvió como agente de información, a diferencia de sus contemporános británicos.

8 VON OPPENHEIM, M. Freiherr (1901): «Bericht über im Jahre 1899 ausgeführte Forschungsreise in der Asiatischen Türkei», Zeitschrift der Gesellschaft für Erdkunde zu Berlin, 36, pp. 69-99.

9 NiPPA, A. (2003): «Tugendreiche Männer. Beduinenforschung», en TEICHMANN, G. y VöLGER, G. (eds.), op. cit., pp. 140-175. ORTHMANN, W. (2003): «Die Ausgrabung am Tell Halaf», en TEICHMANN, G. y VöLGER, G. (eds.), op. cit., pp. 204-247.

10 "Aquí descansa en Dios un hombre que ha amado la ciencia, Oriente, el desierto y el Tell Halaf por él descubierto y excavado»: TEICHMANN, G. (2003): «Grenzgänger zwis- 


\section{El fin dela aventura}

chen Orient und Okzident. Max von Oppenheim 1860-1946», en TEICHMANN, G. y VöLGER, G. (eds.), op. cit., pp. 10-105. Vid. p. 94.

11 Teichmann, G. (2003): op. cit., p. 27, en Teichmann, G. y Völger, G. (eds.), op. cit.

12 La obra apareció publicada en 1904. Hay una versión española reciente en LOTI, P. (2001): Hacia Isfahán. Ediciones Abraxas, Barcelona.

13 BELL, G. (1907): The Desert and the Sown. Heinemann, London. Sobre la persona de Getrud Bell y su vida, puede leerse la biografia escrita por WALLACH, J. (1998): La reina del desierto. Ediciones B, S. A., Barcelona 1998. Pero el tono hagiográfico de la misma -presente incluso en el título escogido- revela que cierto sector de la historiografía anglosajona sigue pensando con los mismos valores y moldes que en la época imperial. Lamentablemente son exactamente los mismos que rigen la política de EEUU y Gran Bretaña en la actualidad.

${ }^{14}$ La verdad es que el pintor no dejó apenas memoria escrita de sus viajes a Oriente, pero lo cierto es que viajó por Turquía, Egipto, Siria y Palestina. Su biógrafo se hace eco de lo difícil que es documentarlos: RodRíGUEz García, S. (1966): Antonio Muñoz Degrain. Pintor valenciano y español. Instituto Alfonso el Magnánimo, Valencia, pp. 125 y 203. Véase también PÉREZ SÁNChEZ, A. E., MARÍ, A., ARIAS ANGLÉs, E. (1988): Pintura orientalista española (1830-1930). Fundación Banco Exterior Madrid, pp.46 y 124-131.

15 REYNA, F. (s/f.): Historia del ballet. Ediciones Daimon / Manuel Tamayo, Madrid Barcelona - México, p. 139. Bourcier, P. (1981): Historia de la danza en Occidente. Editorial Blume, Barcelona, pp. 184-185.

16 Chevalier, N. (2005): Sur le chemin de la Perse. Un archéologue photographe en 1912. Musée du Louvre, Paris. Pp. 2-3.

17 Por cierto y como es bien conocido, uno de los cuatro episodios de la película se desarrolla en la Babilonia de Nabónido y Baltasar, que Griffith reconstruyó en gigantescos decorados, parcialmente inspirados en los resultados de las excavaciones alemanas que dirigía todavía Robert Koldewey. Así GUBERn, R. (1995): Historia del cine. Editorial Lumen, Barcelona, pp. 105-107. También RUIZ, L. E. (2000): Obras pioneras del cine mudo. Orígenes y primeros pasos (1895-1917). Ediciones Mensajero, S. A., Bilbao, p. 392-395. Ya en los años sesenta, el llamado género "peplum" tomaría temas de la antigüedad oriental, recreada con una buena dosis de fantasía, con títulos como Le sette folgori di Assur (1961) de Silvio Amadio, Io, Semiramide (1963) de Primo Zeglio o L'eroe di Babilonia, de Siro Marcellini, el mismo año. Véase EsPAÑA, R. de (1997): El peplum. La Antigüedad en el cine. Ediciones Glenat, S. L. (sin lugar de edición), pp. 98 y 101, 94-95 y 101, y 92, 101-102 respectivamente.

18 Naturalmente, más allá de que Lawrence adoptara una postura de mayor integridad, sus recuerdos de la campaña están lejos de ser imparciales y, desde luego, de cualquier aproximación a lo que entendemos por literatura de viajes o de redescubrimiento de los pueblos del Oriente antiguo o moderno. Una edición española de su famoso The Seven Pillars of Wisdom en LAWRENCE, Th. E. (1986): Los siete pilares de la Sabiduría. Ediciones Júcar, Madrid.

19 Sobre la peculiar personalidad de Harry St John Philby y su papel en Arabia véase BIDwell, R. (1976): Travellers in Arabia. The Hamlyn Publishing Group Limited, London, pp. 96-115.

20 El análisis que hace E.W Said de sus escritos, motivaciones y acciones es demoledor. Naturalmente, la leyenda occidental crea a un Lawrence salvador de los árabes, y a una Gertrud Bell como dueña de la voluntad de Faysal, perpetuando el mito de superiores e inferiores. Por mucho que declaren su amor por Oriente, en todo se descubre su in- 
nato sentimiento de superioridad, y su disgusto cuando los árabes no siguen sus indicaciones. Es imprescindible la lectura de SAID, E. W. (1990): op. cit.

21 SAINT-Prot, Ch. (1999): op. cit. p. 110.

22 SAINT-Prot, Ch. (1999): op. cit., pp. 115-116.

23 Sobre Agatha Christie y su relación con Oriente y la arqueología es imprescindible TrÜMPleR, Ch. (ed.) (1999): Agatha Christie und der Orient. Kriminalistik und Archäologie. Ruhrlandmuseum, Essen.

${ }^{24}$ Audouin-Dubreuil, A. (2002): La Croisière jaune. Sur la route de la soie. Éditions Glénat, Grenoble.

25 GorsheninA, Sv. (2000): La route de Samarcande. L'Asie Centrale dans l'objetif des voyaguers d'autrefois. Éditons Olizane, Genève, pp. 205-297: GoRSHENINA, Sv. (2003): Explorateurs en Asie Centrale. Voyageurs et aventuriers de Marco Polo à Ella Maillart. Éditions Olizane, Genève, pp. 417-420.

26 Existen versiones españolas de sus libros más célebres: THESIGER, W. (1998): Arenas de Arabia. Ediciones Península, S. A., Barcelona. THESIGER, W. (2001): Los árabes de las marismas. Ediciones Península, S. A., Barcelona. Una biografía de reciente publicación sobre W. Thesiger incluye algunas valoraciones sorprendentes sobre Oriente y la política de sus países, debidas a su autor español: LEGUINECHE, M. (2004): El último explorador. La vida del legendario Wilfred Thesiger. Editorial Seix Barral, S. A., Barcelona 2004. 